\title{
Feasibility of Underwater Endoscopic Mucosal Resection for Colorectal Lesions: A Single Center Study in Japan
}

\author{
Takuji Kawamura ${ }^{\text {a, b }}$, Hiroaki Sakai ${ }^{a}$, Tomoya Ogawa ${ }^{a}$, Naokuni Sakiyama ${ }^{a}$, Yuki Ueda ${ }^{a}$, \\ Atsushi Shirakawa ${ }^{a}$, Yusuke Okada ${ }^{a}$, Kasumi Sanada ${ }^{a}$, Kojiro Nakasea ${ }^{a}$, Koichiro Mandai ${ }^{a}$, \\ Azumi Suzuki ${ }^{a}$, Atsuhiro Morita ${ }^{\text {a }}$, Kiyohito Tanaka ${ }^{\mathrm{a}}$, \\ Koji Uno ${ }^{\text {a }}$ Kenjiro Yasuda ${ }^{\mathrm{a}}$
}

\begin{abstract}
Background: Underwater endoscopic mucosal resection (U-EMR) has emerged as an alternative technique for the resection of colorectal lesions. This study aimed to evaluate our initial experience using UEMR.

Methods: This is a single-center, retrospective case series study. We analyzed the clinical outcomes of consecutive patients who underwent U-EMR in our endoscopy center, from December 2015 to February 2017.

Results: Our analysis included 64 lesions, contributed by 38 patients, with a mean age of 68.6 years (range, 25 to 90 years). The study sample included 33 right-sided and 25 left-sided colon lesions, and seven rectal lesions, with an average size of $16.2 \mathrm{~mm}(6-40 \mathrm{~mm})$. Of these, 46 lesions were polypoid and 18 ones non-polypoid. Histologically, 31 lesions were low-grade adenomas, eight ones were high-grade adenomas, 11 were mucosal cancers, four were submucosal cancers, and 10 were classified as "others". En bloc resection was achieved in 52 (81\%) lesions, with an en bloc resection rate of $95 \%$ for lesions $<20$ $\mathrm{mm}$ and $55 \%$ for lesions $\geq 20 \mathrm{~mm}$. Complete resection of neoplastic epithelial lesions, defined by a negative pathological margin, was achieved in 32 of 59 neoplastic epithelial lesions (54\%). We identified three cases $(5 \%)$ of post-procedural bleeding and one case of perforation $(2 \%)$.
\end{abstract}

Conclusions: U-EMR can be feasibly used for resection of colonic lesions, including lesions $\geq 20 \mathrm{~mm}$, although the en bloc resection rate for these lesions was lower than for lesions $<20 \mathrm{~mm}$.

Keywords: Endoscopic mucosal resection; Colorectal neoplasms; Polyps

Manuscript submitted April 9, 2018, accepted July 18, 2018

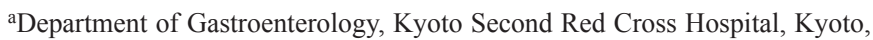
Japan

${ }^{\mathrm{b} C o r r e s p o n d i n g ~ A u t h o r: ~ T a k u j i ~ K a w a m u r a, ~ 355-5 ~ H a r u o b i-c h o, ~ K a m i g y o-k u, ~}$ Kyoto City, Kyoto 602-8026, Japan. Email: kawamurat@kyoto2.jrc.or.jp

doi: https://doi.org/10.14740/gr1021w

\section{Introduction}

Colorectal cancer (CRC) is one of the most commonly diagnosed cancers worldwide [1]. Endoscopic resection of colorectal neoplastic epithelial lesions can prevent CRC [2,3]. Endoscopic mucosal resection, performed using injection of physiological saline into the submucosa to a separate lesion from the muscularis propria (conventional endoscopic mucosal resection (CEMR)), is widely used as a resection technique. In recent years, however, "underwater" EMR (U-EMR) has emerged as an alternative technique, in which the lumen is filled with water to "float" both the mucosa and submucosa [4-11]. Immersion of the lesion in water reduces its diameter, compared to air insufflation, which makes resection of large lesions easier than with C-EMR [8]. U-EMR is also reported as a useful salvage procedure for recurrent colorectal adenoma after piecemeal endoscopic resection [12], or for lesions involving the appendiceal orifice [13].

In Japan, endoscopic submucosal dissection (ESD) is widely performed for laterally spreading tumors [14], but its indication for colorectal ESD technique is limited to lesions $\geq 20 \mathrm{~mm}$ in diameter. Furthermore, because of its technical difficulty, not all lesions $\geq 20 \mathrm{~mm}$ can be resected using ESD and, therefore, piecemeal EMR is still widely performed for some neoplastic epithelial lesions $\geq 20 \mathrm{~mm}$ [14]. On the other hand, the frequency of cold polypectomy, which does not require an electrosurgical unit, is increasing, although use of this technique is generally limited to lesions $<10 \mathrm{~mm}$ in diameter $[15,16]$. Therefore, EMR is still one of the most frequently used techniques for the treatment of colorectal lesions in Japan. EMR, however, is usually performed under air or carbon deoxidate insufflation, with evidence for U-EMR being limited. As such, our aim in this study was to evaluate our initial experience with U-EMR in a Japanese setting.

\section{Materials and Methods}

\section{Study design}

This is a single-center, retrospective case series. We analyzed the clinical outcomes of consecutive patients who underwent U-EMR in our endoscopy center, from December 2015 to Feb- 

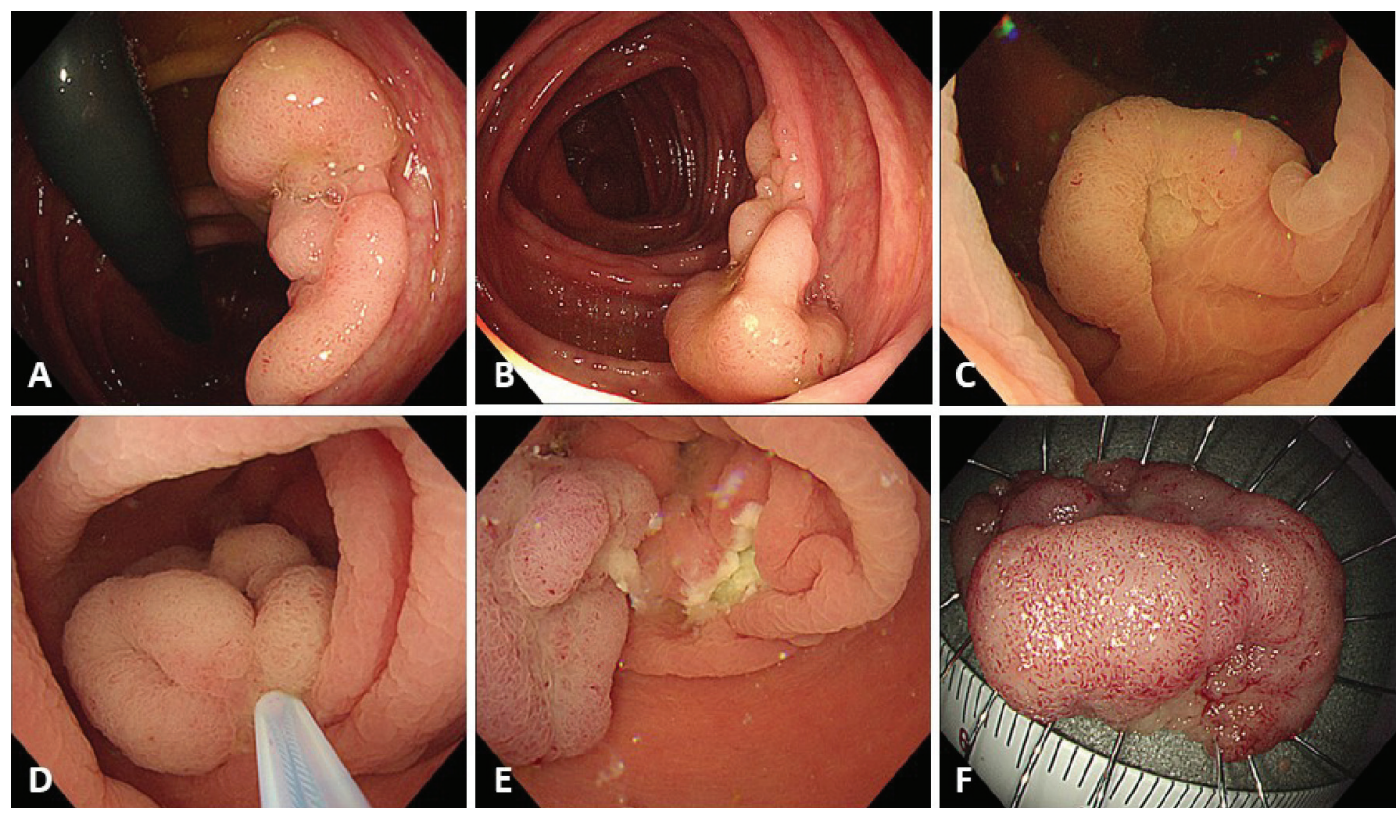

Figure 1. Procedure for underwater endoscopic mucosal resection (U-EMR). (A, B) A sessile lesion about $30 \mathrm{~mm}$ located in the ascending colon. (C) The lumen at the site of the lesion was filled with water, using the water-jet system, and the lesion was floated in the lumen. (D) The lesion was snared, using a 33-mm snare, and the lesion was tightened-up. (E) The mucosal defect after U-EMR was usually smaller than after conventional EMR. (F) Resected specimen after successful en bloc resection.

ruary 2017. Endoscopic resection of colorectal lesions, 10 to 19 $\mathrm{mm}$ in diameter, was performed using the U-EMR technique. All procedures were either performed or supervised by one staff endoscopist (TK), who has performed over 1,000 cases of C-EMR, but having no prior experience with U-EMR before the study period. Generally, at our center, cold polypectomy is used for lesions $<10 \mathrm{~mm}$. However, U-EMR was introduced for suspected cases of high-grade adenoma, even if the lesion was less $<10 \mathrm{~mm}$. Furthermore, although ESD is usually used for lesions with a diameter $\geq 20 \mathrm{~mm}$ that are suspected to be malignant, U-EMR was attempted for large diameter lesions in cases in which successful en bloc resection was expected. U-EMR was avoided when bowel preparation was poor.

Clinical outcomes were the en bloc resection rate, the complete resection rate, defined by a negative pathological margin for specimen successfully resected en-bloc, and postprocedural complications. Post-procedural bleeding was defined as hemorrhage after colonoscopy requiring endoscopic hemostasis. The en bloc resection rate and complications were evaluated for all lesions, whereas the complete resection rate was analyzed only for lesions with a neoplastic histology (lowor high-grade adenoma, mucosal or submucosal cancer, sessile serrated adenoma/polyp, and traditional serrated adenoma). Written informed consent was obtained from each patient before the procedure. The protocol for this retrospective analysis of our outcomes was approved by the institutional review board of Kyoto Second Red Cross Hospital.

\section{Endoscopic procedure and data collection}

For bowel preparation, magnesium citrate and/or sodium pico- sulfate hydrate were administered on the day prior to colonoscopy, with a $2 \mathrm{~L}$ polyethylene glycol preparation performed on the morning of the procedure. A standard high-definition videocolonoscope (Olympus, Tokyo, Japan), with a water jet system (i.e. CF-HQ290, PCF-H290), was used. Water (tap water or pure water) was prepared in the water jet system and injected until the lumen at the site of the lesion was filled (Fig. 1). Local injection into the submucosa was not performed when the lesion could be adequately floated. A 10 or $33 \mathrm{~mm}$ snare (Captivator II, Boston Scientific, Natick, Massachusetts, USA) or a 13-mm rotatable snare (Boston Scientific) was used. Marking around a lesion before resection was not performed. The high-frequency ESG-100 generating device (Olympus, Tokyo, Japan) was used, with the high-frequency setting placed either on "pulse-cut slow" $(20 \mathrm{~W})$ or "forced coagulation 2" (15 W). After resection, retrieved lesions were fixed to a firm sponge for histological evaluation of the base of the lesion and its lateral margin. The lesions were soaked in formalin for $>12 \mathrm{~h}$ and subsequently cut into formalin-fixed specimen at $2 \mathrm{~mm}$ intervals by a pathologist. Hematoxylin-eosin staining was performed for pathological diagnosis.

All data were collected in an endoscopic database (Solemio Endo, Olympus, Tokyo, Japan), with the location, size and morphology of the lesion inputted by the endoscopist soon after each procedure.

\section{Results}

Our analysis included 64 lesions, contributed by 38 patients, with a mean age of 68.6 years (range, 25 to 90 years; Table 1 ). Among the 64 lesions, 33 were right-sided lesions (oral side, 
Table 1. Patient and Lesion Characteristics

\begin{tabular}{|c|c|}
\hline Number of cases & 64 lesions in 38 cases \\
\hline Mean age, years (range) & $68.6(25-90)$ \\
\hline Male sex, N (\%) & $26(68)$ \\
\hline Mean size of lesions, mm (range) & $16.2(6-40)$ \\
\hline$<10 \mathrm{~mm}, \mathrm{~N}(\%)$ & $8(13)$ \\
\hline $10-19 \mathrm{~mm}, \mathrm{~N}(\%)$ & $34(53)$ \\
\hline $20-29 \mathrm{~mm}, \mathrm{~N}(\%)$ & $15(23)$ \\
\hline$\geq 30 \mathrm{~mm}, \mathrm{~N}(\%)$ & $7(11)$ \\
\hline \multicolumn{2}{|l|}{ Location } \\
\hline Cecum, N (\%) & $9(14)$ \\
\hline Ascending colon, N (\%) & $12(19)$ \\
\hline Transverse colon, $\mathrm{N}(\%)$ & $12(19)$ \\
\hline Descending colon, N (\%) & $7(11)$ \\
\hline Sigmoid colon, N (\%) & $17(27)$ \\
\hline Rectum, N (\%) & $7(11)$ \\
\hline \multicolumn{2}{|l|}{ Morphology } \\
\hline 0 -Is, N (\%) & $33(52)$ \\
\hline 0-Ip, N (\%) & $10(16)$ \\
\hline 0-IIa, N (\%) & $18(28)$ \\
\hline 0-IIa+Is, N (\%) & $3(5)$ \\
\hline \multicolumn{2}{|l|}{ Histology } \\
\hline Low-grade adenoma, N (\%) & $31(48)$ \\
\hline High-grade adenoma, N (\%) & $8(13)$ \\
\hline Mucosal cancer, N (\%) & $11(17)$ \\
\hline Submucosal cancer, N (\%) & $4(6)$ \\
\hline Sessile serrated adenoma/polyp, N (\%) & $4(6)$ \\
\hline Traditional serrated adenoma, N (\%) & $1(2)$ \\
\hline Hyperplastic polyp, N (\%) & $3(5)$ \\
\hline Inflammatory polyp, N (\%) & $2(3)$ \\
\hline
\end{tabular}

from the splenic flexure), 24 left-sided and seven rectal. The relevant characteristics of the lesions were as follows: size, mean $16.2 \mathrm{~mm}$ (range, 6 to $40 \mathrm{~mm}$ ); 42 lesions had a diameter $<20 \mathrm{~mm}(66 \%)$, with the other 22 lesions (43\%) having a diameter $\geq 20 \mathrm{~mm}$; and 46 lesions $(72 \%)$ were polypoid and 18 (28\%) non-polypoid. Endoscopic ultrasound (EUS) imaging was performed before U-EMR in only three cases, in the early period of the study, to evaluate the status of the muscularis propria under a water-immersion condition. In all three cases that underwent EUS, we confirmed that only the mucosa and submucosa were floated in the water-immersion lumen, and, therefore, that the muscularis propria did not float. The final histological diagnoses were as follows: 31 low-grade adenomas, eight high-grade adenomas, 11 mucosal cancers, four submucosal cancers, and 10 classified as "others".

En bloc resection was achieved in 52 (81\%) lesions (Table 2 ). The en bloc resection rate was $95 \%$ for lesions $<20 \mathrm{~mm}$ in diameter, compared to $55 \%$ for lesions with a diameter $\geq$
$20 \mathrm{~mm}$. Complete resection was achieved in 32 of the 59 neoplastic epithelial lesions (54\%), with a complete resection rate of $68 \%$ for lesions $<20 \mathrm{~mm}$, compared to $26 \%$ for lesions $\geq$ $20 \mathrm{~mm}$. Negative vertical margins were achieved for all four submucosal cancers, with an adequate depth of tumor invasion evaluated (Table 3 ). Post-procedural bleeding was identified in three lesions $(5 \%)$, with perforation identified in one lesion (2\%); further surgical intervention was not required for treatment of these complications. Submucosal injection was required in only one case, with a $30 \mathrm{~mm}$ lesion located in the ascending colon that could not be adequately floated (Fig. 2). This was the only case of perforation.

\section{Discussion}

In this study, U-EMR was used for the resection of colorectal lesions having an average diameter of $16.2 \mathrm{~mm}$. An en bloc resection rate of $81 \%$ was achieved, with a complete resection rate of $58 \%$. The en bloc resection rate for lesions $<20$ $\mathrm{mm}$ was $95 \%$, compared to $55 \%$ for lesions $\geq 20 \mathrm{~mm}$. Postprocedural bleeding and perforation, as complications, were identified in three $(5 \%)$ and one $(2 \%)$ lesion, respectively.

Previous studies evaluating U-EMR reported en bloc resection rates of 45 to $76 \%$ for tumors 18 to $30 \mathrm{~mm}$ in diameter [7-10]. Siau et al [10] reported en bloc resection rates of $82.9 \%$ for lesions 10 - $20 \mathrm{~mm}$ in diameter, $43.8 \%$ for a $20-30 \mathrm{~mm}$ diameter, $36.8 \%$ for a diameter of $30-40 \mathrm{~mm}$, and $3.8 \%$ for a diameter $>40 \mathrm{~mm}$. By comparison, for C-EMR, using $0.13 \%$ hyaluronic acid solution, Yoshida et al [17] reported en bloc resection rates of $95.3 \%$ for lesions with a diameter of $5-10$ $\mathrm{mm}$ and $85.1 \%$ for a diameter of lesions with a diameter of 10 - $20 \mathrm{~mm}$. Saito et al [18] reported a C-EMR en bloc resection rate of $33 \%$ for lesions with a diameter $\geq 20 \mathrm{~mm}$, compared to a rate of $84 \%$ for ESD. Similarly, in our study, the en bloc resection rate decreased when U-EMR was performed for lesions $\geq 20 \mathrm{~mm}$ in diameter.

With regard to complications, in their review of 4,000 cases of conventional polypectomy for polyps with an average diameter of $11 \mathrm{~mm}$, Heldwein et al [19] reported a rate of postprocedural bleeding of $8.6 \%$ and a rate of perforation of $1.1 \%$. For tumors with a diameter $>20 \mathrm{~mm}$, a meta-analysis revealed a post-procedural bleeding rate of $6.5 \%$ and a rate of perforation of $1.5 \%$ [20]. The post-procedural bleeding rate in our study was $5 \%$ and the rate of perforation was $2 \%$. Therefore, the rate of complication after U-EMR was equivalent to that of C-EMR. With the rates of success and complications being comparable for U-EMR and C-EMR, the clinical advantages of U-EMR over C-EMR should be considered.

With U-EMR, a submucosal injection to lift the lesion is usually unnecessary and, therefore, there is no potential risk of dissemination of the tumor and post-EMR syndrome due to leakage of the solution out of the colonic wall. As a secondary benefit, U-EMR avoids the cost of the injection needle and solution. A third clinical advantage is that piecemeal resection is easier using U-EMR than C-EMR in cases when en bloc resection cannot be achieved. In their case review of colonic tumors $\geq 15 \mathrm{~mm}$ in diameter, many of which were resected using 
Table 2. Study Outcomes

\begin{tabular}{|ll}
\hline $\begin{array}{l}\text { En bloc resection rate } \\
\text { Overall, \% }\end{array}$ & $81(52 / 64$ lesions $)$ \\
$<10 \mathrm{~mm}, \%$ & $100(8 / 8)$ \\
$10-19 \mathrm{~mm}, \%$ & $94(32 / 34)$ \\
$20-29 \mathrm{~mm}, \%$ & $53(8 / 15)$ \\
$\geq 30 \mathrm{~mm}, \%$ & $57(4 / 7)$ \\
Complete resection rate & \\
\hline Overall, \% & $54(32$ of 59 neoplastic epithelial lesions $)$ \\
$<10 \mathrm{~mm}, \%$ & $88(7 / 8)$ \\
$10-19 \mathrm{~mm}, \%$ & $63(20 / 32)$ \\
$20-29 \mathrm{~mm}, \%$ & $25(3 / 12)$ \\
$\geq 30 \mathrm{~mm}, \%$ & $29(2 / 7)$ \\
Post procedural bleeding, N (\%) & $3(5)$ \\
Perforation, N (\%) & $1(2)$ \\
\hline
\end{tabular}

$\ddagger$ Complete resection rate was defined by a negative pathological margin of resected specimen that was obtained by successful en bloc resection.

a piecemeal approach, Schenck et al reported a significantly lower rate of recurrence for U-EMR than C-EMR [11]. Fourth, U-EMR allows for easier clipping after resection than C-EMR. Although we did not specifically measure the mucosal defect after U-EMR, based on experience, the endoscopist considered the defect to be smaller for U-EMR than C-EMR.

As we mentioned above, U-EMR technique does not require submucosal injection, as per the original work by Binmoeller et al [4]. However, Siau et al reported that they used submucosal injection in approximately $30 \%$ of U-EMR cases [10]. In our case series, submucosal injection was required in one case in which adequate floating of the lesion could not be achieved. This was the only case of perforation we encountered. Ponugoti et al reported a case of perforation during U-EMR using a retroflexion technique in the ascending colon [21]. They suggested that the perforation resulted from stretching of the colonic wall by the retroflexed colonoscope, which prevented the lesion from being adequately floated. In our case of perforation, stretching of the colonic wall by the submucosal injection is likely to have been the cause. Therefore, care should be taken when performing U-EMR with submucosal injection.
U-EMR is usually performed for sessile lesions. However, 10 pedunculated polyps were included in our case series. Snaring of pedunculated polyps is usually easier to perform than for sessile lesions. However, snaring of pedunculated polyps is difficult when these are not aligned with gravity. Floating of the pedunculated polyps during U-EMR procedure makes snaring easier. Therefore, U-EMR would be useful not only for sessile lesions, but also for pedunculated lesions.

This study has several limitations that need to be acknowledged. First, this is a single-center, retrospective case series and, therefore, the possibility of selection bias cannot be excluded. Furthermore, important data, such as procedure time, was not obtained. Second, the study sample is small. Third, the long-term outcomes have not been evaluated. Even when we could not achieve en bloc resection, we removed all of lesions completely using a piecemeal resection technique. Careful follow-up is needed, especially for cases with piecemeal resection.

Despite these limitations, our data supports the clinical feasibility of U-EMR for the treatment of colorectal lesions. Although lesions $\geq 20 \mathrm{~mm}$ could be resected en bloc using the

Table 3. Cases of Submucosal Cancer in This Study

\begin{tabular}{|c|c|c|c|c|}
\hline Age (years) & 67 & 71 & 90 & 85 \\
\hline Sex & $\mathrm{F}$ & $\mathrm{M}$ & $\mathrm{M}$ & M \\
\hline Location & Ascending colon & Ascending colon & Sigmoid colon & Cecum \\
\hline Morphology & 0-IIa+Is (LST-G) & 0 -Is & 0-IIa (LST-NG) & 0 -Is \\
\hline En bloc resection & No & No & Yes & Yes \\
\hline Lateral margin & N/A & N/A & + & - \\
\hline Base margin & - & - & - & - \\
\hline
\end{tabular}

LST-NG: laterally spreading tumor, non-granular type; LST-G: laterally spreading tumor, granular type; N/A: not applicable. 

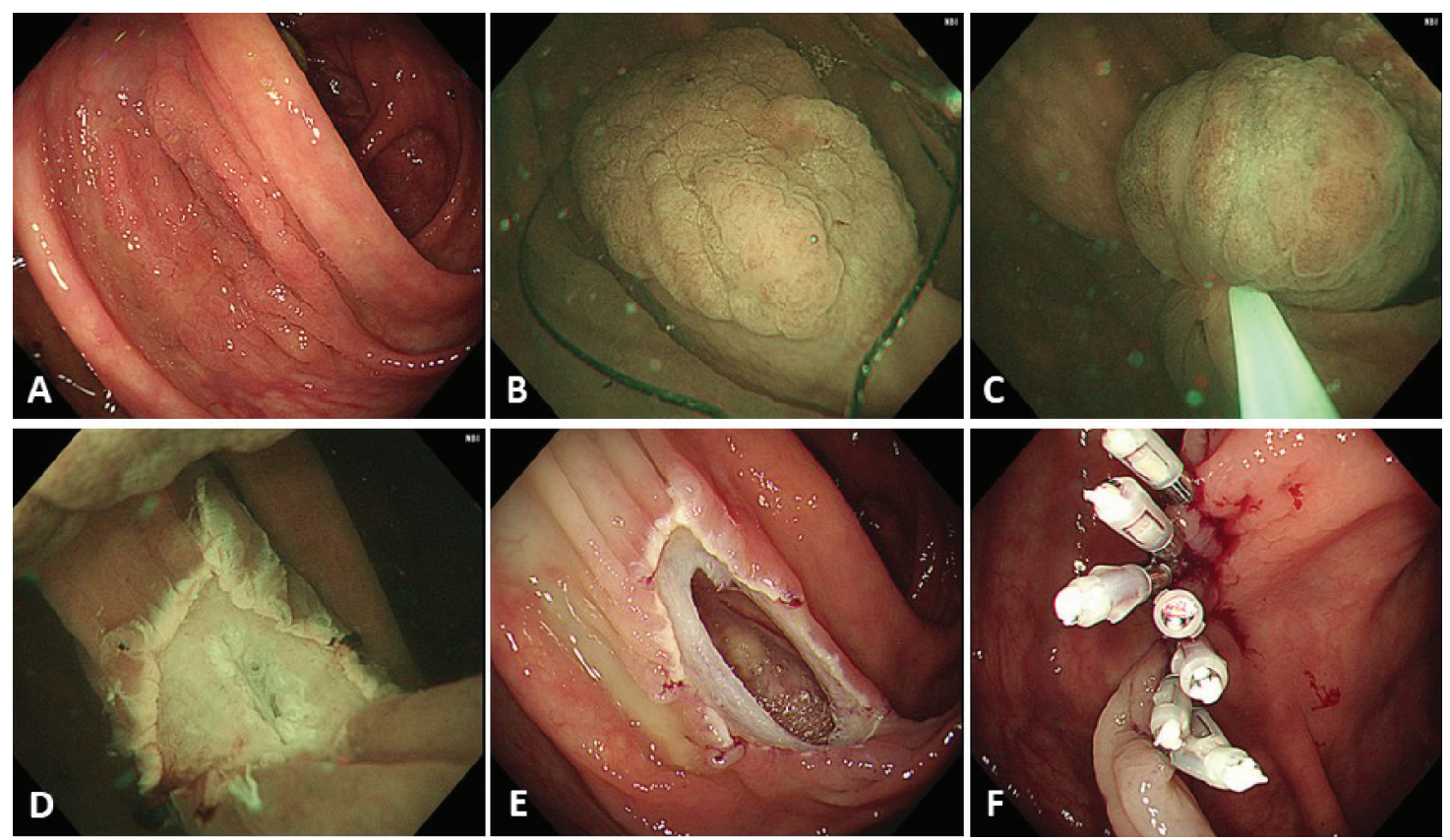

Figure 2. A case of perforation. (A) A laterally spreading, granular type lesion about $30 \mathrm{~mm}$ located in the ascending colon. (B) Adequate floating of the lesion could not be achieved and, therefore, submucosal injection, using normal saline, was performed before snaring. (C) The lesion was snared, using a 33-mm snare, and the lesion was tightened-up. (D) En bloc resection was achieved but the muscularis propria was slightly injured at the center of the mucosal defect. (E) An obvious perforation was identified after gas insufflation in the lumen. (F) Endoscopic clipping was performed, and surgical intervention was not required.

U-EMR technique, the en bloc resection rate was greater for lesions $<20 \mathrm{~mm}$ than for lesions $\geq 20 \mathrm{~mm}$.

\section{Acknowledgments}

We would like to thank Editage (www.editage.jp) for English language editing. We also wish to thank the staff of endoscopy center in our hospital for their cooperation.

\section{Conflict of Interest}

The authors declare there is no conflict of interest.

\section{References}

1. Torre LA, Bray F, Siegel RL, Ferlay J, Lortet-Tieulent J, Jemal A. Global cancer statistics, 2012. CA Cancer J Clin. 2015;65(2):87-108.

2. Zauber AG, Winawer SJ, O'Brien MJ, Lansdorp-Vogelaar I, van Ballegooijen M, Hankey BF, Shi W, et al. Colonoscopic polypectomy and long-term prevention of colorectal-cancer deaths. N Engl J Med. 2012;366(8):687-696.

3. Loberg M, Kalager M, Holme O, Hoff G, Adami HO, Bretthauer M. Long-term colorectal-cancer mortality after adenoma removal. N Engl J Med. 2014;371(9):799807.

4. Binmoeller KF, Weilert F, Shah J, Bhat Y, Kane S. "Un- derwater" EMR without submucosal injection for large sessile colorectal polyps (with video). Gastrointest Endosc. 2012;75(5):1086-1091.

5. Wang AY, Flynn MM, Patrie JT, Cox DG, Bleibel W, Mann JA, Sauer BG, et al. Underwater endoscopic mucosal resection of colorectal neoplasia is easily learned, efficacious, and safe. Surg Endosc. 2014;28(4):13481354.

6. Uedo N, Nemeth A, Johansson GW, Toth E, Thorlacius $\mathrm{H}$. Underwater endoscopic mucosal resection of large colorectal lesions. Endoscopy. 2015;47(2):172-174.

7. Curcio G, Granata A, Ligresti D, Tarantino I, Barresi L, Liotta R, Traina M. Underwater colorectal EMR: remodeling endoscopic mucosal resection. Gastrointest Endosc. 2015;81(5):1238-1242.

8. Binmoeller KF, Hamerski CM, Shah JN, Bhat YM, Kane SD, Garcia-Kennedy R. Attempted underwater en bloc resection for large $(2-4 \mathrm{~cm})$ colorectal laterally spreading tumors (with video). Gastrointest Endosc. 2015;81(3):713-718.

9. Amato A, Radaelli F, Spinzi G. Underwater endoscopic mucosal resection: The third way for en bloc resection of colonic lesions? United European Gastroenterol J. 2016;4(4):595-598.

10. Siau K, Ishaq S, Cadoni S, Kuwai T, Yusuf A, Suzuki N. Feasibility and outcomes of underwater endoscopic mucosal resection for $>/=10 \mathrm{~mm}$ colorectal polyps. Surg Endosc. 2018;32(6):2656-2663.

11. Schenck RJ, Jahann DA, Patrie JT, Stelow EB, Cox DG, Uppal DS, Sauer BG, et al. Underwater endoscopic mu- 
cosal resection is associated with fewer recurrences and earlier curative resections compared to conventional endoscopic mucosal resection for large colorectal polyps. Surg Endosc. 2017;31(10):4174-4183.

12. Kim HG, Thosani N, Banerjee S, Chen A, Friedland S. Underwater endoscopic mucosal resection for recurrences after previous piecemeal resection of colorectal polyps (with video). Gastrointest Endosc. 2014;80(6):10941102 .

13. Binmoeller KF, Hamerski CM, Shah JN, Bhat YM, Kane SD. Underwater EMR of adenomas of the appendiceal orifice (with video). Gastrointest Endosc. 2016;83(3):638642.

14. Tanaka S, Kashida H, Saito Y, Yahagi N, Yamano H, Saito $\mathrm{S}$, Hisabe T, et al. JGES guidelines for colorectal endoscopic submucosal dissection/endoscopic mucosal resection. Dig Endosc. 2015;27(4):417-434.

15. Matsuura N, Takeuchi Y, Yamashina T, Ito T, Aoi K, Nagai $\mathrm{K}$, Kanesaka $\mathrm{T}$, et al. Incomplete resection rate of cold snare polypectomy: a prospective single-arm observational study. Endoscopy. 2017;49(3):251-257.

16. Kawamura T, Takeuchi Y, Asai S, Yokota I, Akamine E, Kato M, Akamatsu T, et al. A comparison of the resection rate for cold and hot snare polypectomy for 4-9 mm colorectal polyps: a multicentre randomised controlled trial (CRESCENT study). Gut. 2017;60(1):gutj nl-2017-314215.

17. Yoshida N, Naito Y, Inada Y, Kugai M, Yagi N, Inoue K, Okuda T, et al. Multicenter study of endoscopic mucosal resection using $0.13 \%$ hyaluronic acid solution of colorectal polyps less than $20 \mathrm{~mm}$ in size. Int J Colorectal Dis. 2013;28(7):985-991.

18. Saito Y, Fukuzawa M, Matsuda T, Fukunaga S, Sakamoto T, Uraoka T, Nakajima T, et al. Clinical outcome of endoscopic submucosal dissection versus endoscopic mucosal resection of large colorectal tumors as determined by curative resection. Surg Endosc. 2010;24(2):343-352.

19. Heldwein W, Dollhopf M, Rosch T, Meining A, Schmidtsdorff G, Hasford J, Hermanek P, et al. The Munich Polypectomy Study (MUPS): prospective analysis of complications and risk factors in 4000 colonic snare polypectomies. Endoscopy. 2005;37(11):1116-1122.

20. Hassan C, Repici A, Sharma P, Correale L, Zullo A, Bretthauer M, Senore C, et al. Efficacy and safety of endoscopic resection of large colorectal polyps: a systematic review and meta-analysis. Gut. 2016;65(5):806-820.

21. Ponugoti PL, Rex DK. Perforation during underwater EMR. Gastrointest Endosc. 2016;84(3):543-544. 